\title{
Peningkatan Literasi Digital Marketing UMKM Kota Tasikmalaya
}

\author{
Mira Nurfitriya1, Azizah Fauziyah², Tika Annisa Lestari Koeswandi ${ }^{3}$, Ismail \\ Yusuf $^{4}$, Nizza Nadya Rachmani ${ }^{5}$ \\ Universitas Pendidikan Indonesia ${ }^{1,2,3,4,5}$ \\ Korespondensi: miranurfitriya@upi.edu ${ }^{1}$, azizahfauziyah@upi.edu ${ }^{2}, \underline{\text { tikakoeswandi@upi.edu }}{ }^{3}$, \\ ismail_yusuf@upi.edu ${ }^{4}$, nadyarachmani@upi.edu ${ }^{5}$
}

\begin{abstract}
The purpose of this community service $(P k M)$ is to find out the difference in literacy levels before and after being given training on digitalization of MSME marketing. The object of research in this study were 11 participants of the Tasikmalaya City MSME training. This service used the Focus Group Discussion (FGD) method, and to analyze the different levels of digital marketing literacy using Paired t-test as a test tool. The results obtained indicate that the digital marketing literacy level of MSMEs in Tasikmalaya City is quite low due to the less optimal use of the internet in its business operations. In addition, there is a significant difference between the level of digital marketing literacy before and after the training, which is indicated by the significance value (2tailed) of the paired t-test results of 0.013, which means that the results of the participants' understanding of digital marketing literacy before and after the training is not the same (different).
\end{abstract}

Keywords: digital marketing literacy, training, MSME

\begin{abstract}
Abstrak
Tujuan pengabdian kepada masyarakat $(\mathrm{PkM})$ ini adalah untuk mengetahui perbedaan tingkat literasi sebelum dan sesudah diberikan pelatihan digitalisasi marketing UMKM. Objek penelitian dalam penelitian ini adalah 11 peserta pelatihan UMKM Kota Tasikmalaya. Pengabdian ini menggunakan Metode Focus Group Discussion (FGD), dan untuk menganalisis perbedaan tingkat literasi digital marketing menggunakan menggunakan Paired t-test sebagai alat ujinya. Hasil yang diperoleh menunjukkan bahwa tingkat literasi digital marketing UMKM di Kota Tasikmalaya cukup rendah karena kurang optimalnya penggunaan internet dalam operasional usahanya. Selain itu, terdapat perbedaan yang signifikan antara tingkat literasi digital marketing sebelum dan sesudah dilakukan pelatihan, yang ditunjukkan dengan nilai signifikansi (2-tailed) hasil uji paired t-test sebesar 0, 013, yang berarti bahwa hasil pemahaman literasi digital marketing peserta sebelum dan sesudah pelatihan tidak sama (berbeda).
\end{abstract}

Kata kunci: literasi digital marketing, pelatihan, UMKM 
Mira Nurfitriya, Azizah Fauziyah, Tika Annisa Lestari Koeswandi, Ismail Yusuf, \& Nizza Nadya Rachmani

\section{A. Pendahuluan}

Usaha Mikro Kecil dan Menengah (UMKM) memiliki peran yang sangat penting pada perekonomian Indonesia. Karena UMKM sangat berpengaruh terhadap kondisi perekonomian Indonesia dimana kontribusi UMKM terhadap perekonomian Indonesia sangatlah besar (Thaha, 2020). Selain itu, menumbuhkan dan mengembangkan usaha untuk membangun perekonomian nasional adalah tujuan dari UMKM di Indonesia (Setiani, 2020).

Pesatnya kemajuan teknologi pada era revolusi industri 4.0 dan society 5.0 ini menyebabkan persaingan dalam dunia perdagangan semakin ketat. Selain itu, tren strategi bisnis pun berubah yang semula menggunakan cara konvensional, kemudian beralih menjadi digital. Guna mengoptimalkan pemasaran, para pelaku Usaha Mikro Kecil dan Menengah (UMKM) mulai memanfaatkan perkembangan teknologi digital, dengan tujuan membuka pasar lebih luas lagi sehingga dapat membantu perkembangan UMKM itu sendiri.

Seperti yang dijelaskan oleh Harini (2020) pemberdayaan UMKM di tengah era globalisasi dan tingginya persaingan pasar membuat UMKM harus mampu menghadapi berbagai tantangan, cepat tanggap dalam berdaptasi dengan perubahan yang berkembang saat ini, seperti meningkatkan inovasi produk dan jasa, pengembangan sumber daya manusia dan teknologi, serta perluasan area pemasaran.

Di Indonesia sendiri, perkembangan teknologi yang kian cepat menyebabkan bermunculan berbagai macam marketplace yang menjadi media utama dalam pemasaran digital misalnya seperti Shopee, Tokopedia, Lazada, Bukalapak, dan lainlain. (Susanto et al., 2020) menjelaskan bahwa "Indonesia salah satu negara yang mengalami perkembangan dengan penetrasi $56 \%$ aktif di media sosial, jumlah pengguna internet 150 juta dan aktif di media sosial 150 juta pengguna, merupakan pasar yang sangat potensial untuk UMKM yang akan memulai dan terus menggunakan media sosial untuk melakukan promosi dan penjualan online".

Terdapat sekitar 8 juta UMKM atau 13\% dari total UMKM yang ada yang telah bergabung dengan marketplace yang sudah ada saat ini (Syahrianto, 2020). Data tersebut menggambarkan bahwa tingkat pemasaran digital di Indonesia masih perlu ditingkatkan, mengingat penggunaan marketplace sebagai media utama pemasaran masih sangat kecil. Di Kota Tasikmalaya sendiri, berdasarkan data pra-penelitian yang telah dilakukan, perkembangan UMKM dipengaruhi oleh beberapa komponen yang masih perlu ditingkatkan. Yang pertama, sekitar 47,5 \% sumber daya manusia di UMKM Kota Tasikmalaya merupakan lulusan dari tingkat SMA/sederajat dimana disini keterampilan sumber dayanya masih perlu dikembangkan untuk menghasilkan produk yang berdaya saing tinggi. Kedua, dari pengelolaan keuangannya, sekitar 35,1 $\%$ UMKM belum menerapkan sistem pengelolaaan keuangan yang terorganisir, tentu hal ini akan menjadi hambatan tersendiri bagi para pelaku UMKM dalam melakukan kegiatan usahanya. Namun yang menjadi sorotan utama adalah perihal penggunaan internet yang masih kurang optimal juga di kalangan pelaku UMKM yang ada di Kota Tasikmalaya, dimana yang menjadi dasar pemasaran di era digital ini adalah penggunaan internet dalam pemasaran. Meskipun beberapa pelaku UMKM di Kota 
Tasikmalaya telah menggunakan internet dalam aktivitas penjualannya, namun meraka masih belum mampu mengoptimalkan teknologi digital dalam memasarkan produknya. Hal tersebut ditandai dengan penggunaan media promosi yang digunakan masih terbatas pada media WhatsApp serta media sosial lainnya seperti Facebook dan Instagram.

Penggunaan media promosi oleh UMKM di Kota Tasikmalaya secara keseluruhan berada pada tingkatan yang cukup rendah, seperti pengunaan website masih berada di angka $7 \%$ dari total keseluruhan UMKM yang ada, serta penggunaan e-commerce dalam pemasaran produknya masih berada di angka 6,4 \%. Dengan demikian, peningkatan literasi dasar pemanfaatan pemasaran digital bagi UMKM tidak bisa dipungkiri lagi memang sangat penting dan harus dikembangkan guna bertahan di era ketidakpastian saat ini. Literasi merupakan kemampuan untuk memahami dan menggunakan informasi dalam berbagai format digital, dan sebagai kunci agar pemasaran digital dapat berjalan dengan optimal, karena melalui literasi pemasaran digital, dapat memberikan kemampuan kepada pelaku usaha agar dapat memahami informasi peluang usaha guna meningkatkan kualitas penjualan produk melalui teknologi yang ada (Belshaw, 2011).

Literasi digital membangun konseptualisasi literasi yang terdiri dari empat komponen utama yaitu kemampuan dasar literasi digital (underpinning), latar belakang pengetahuan informasi (background knowledge), kompetensi utama literasi digital (central competencies), serta sikap dan perspektif informasi (attitudes and perspective) (Bawden, 2008). Pertumbuhan informasi yang tidak terkendali menuntut para pelaku UMKM agar lebih responsif terhadap perubahan yang ada. Menurut American Library Association (ALA), untuk menjadi orang yang melek akan informasi, seseorang harus mampu mengetahui kapan informasi itu dibutuhkan dan memiliki kemampuan untuk menemukan, mengevaluasi, dan menggunakan informasi yang dibutuhkan secara efektif (Wooliscroft, 1997). Berdasarkan latar belakang kondisi tersebut peningkatan literasi digital ini sangat penting untuk para pelaku UMKM, khususnya sebagai upaya dalam meningkatkan daya saingnya di pasar.

\section{B. Pelaksanaan dan Metode}

Pelatihan ini menggunakan metode FGD (Focus Group Discussion) melalui eksplorasi suatu isu/fenomena khusus dari diskusi suatu kelompok individu yang terlibat di dalamnya untuk menghasilkan suatu kesepakatan bersama (Kitzinger \& Barbour, 1999). Metode ini berdasarkan segi kepraktisan dan biaya merupakan metode yang hemat biaya, fleksibel, praktis, dan elaboratif (Streubert \& Carpenter, 2003). Serta metode FGD merupakan metode yang memiliki tingkat high face validity dan secara umum berorientasi pada prosedur penelitian (Lehoux, Poland, \& Daudelin. 2006). Metode penelitian FGD kali ini dilakukan secara online dikarenakan kebijakan pemerintah work from home dalam menghadapi pandemik Covid-19. Kegiatan FGD tersebut akan membahas mengenai masalah literasi digital marketing pelaku UMKM dan perannya dalam meningkatkan strategi bersaing UMKM di Kota Tasikmalaya. Dilihat dari analisis dan jenisnya, pemaparan hasil dari kegiatan ini ini menggunakan metode kualitatif yang berfokus pada kualitas literasi digital marketing. 
Mira Nurfitriya, Azizah Fauziyah, Tika Annisa Lestari Koeswandi, Ismail Yusuf, \& Nizza Nadya Rachmani

Evaluasi kegiatan ini dilakukan dalam bentuk pelatihan daring dan kuesioner online yang berisi tes penguji literasi pelaku UMKM di Kota Tasikmalaya mengenai digital marketing. Kuesioner online diberikan sebelum dan setelah pelatihan daring untuk mengukur peningkatan pemahaman dan kemampuan peserta. Pelatihan daring diberikan melalui Google Meet. Adapun kuesioner online diberikan melalui Google Form. Selain itu sebagai proses pendampingan, evaluasi akan diberikan secara berkelanjutan.

Data evaluasi kemudian dianalisis menggunakan uji paired sample t-test dengan persyaratan analisis berupa uji normalitas data. Semua uji asumsi parametric dilakukan pada nilai signifikansi $5 \%$.

\section{Hasil dan Pembahasan}

\section{Gambaran Umum Literasi Digital Marketing UMKM Kota Tasikmalaya}

Pada era revolusi industri 4.0, kecanggihan teknologi semakin pesat dan hal itu banyak mempengaruhi dunia bisnis atau dunia usaha. Usaha Mikro Kecil dan Menengah (UMKM) pastinya harus mempelajari mengenai digital agar dapat beradaptasi dengan pesatnya kemajuan teknologi di era revolusi industri 4.0 saat ini. Karena salah satu hal yang akan berubah dan mempengaruhi dunia usaha adalah Internet of Things (IoT) dimana penggunaan internet untuk suatu usaha menjadi sangat penting. Oleh karena itu, berbagai jenis usaha mikro harus dapat beradaptasi dengan pesatnya kemajuan teknologi, salah satunya dengan memulai menggunakan internet untuk operasional usahanya (Ayodya, 2020).

Kecanggihan teknologi membuat jarak bukan menjadi masalah dalam berkomunikasi, apalagi saat ini sudah banyak sekali media sosial yang memudahkan kita untuk berinteraksi dengan orang-orang yang berada jauh dari jangkauan. Berdasarkan data yang ada di BPS, penggunaan internet mengalami kenaikan dimana yang menggunakan telepeon seluler pada tahun 2020 mencapai $62,84 \%$. Selain itu, yang memiliki komputer juga mengalami kenaikan menjadi 18,83\%. Kenaikan tersebut juga mempengaruhi naiknya penduduk yang mengakses internet dimana pada tahun 2016 penduduk yang mengakses internet sekitar 25,37\% dan pada tahun 2020 penduduk yang mengakses internet mengalami kenaikan menjadi 53,73\%. Hal itu, dapat menjadi peluang yang sangat besar bagi para pelaku usaha UMKM untuk memperluas jangkauan pasar dengan menerapkan digital marketing pada usahanya.

Menurut (Sulaksono \& Zakaria, 2020) "digital marketing adalah kegiatan promosi dan pencarian pasar melalui media digital secara online dengan memanfaatkan berbagai sarana misalnya jejaring sosial". Dengan menerapkan digital marketing pelaku usaha dapat dengan mudah berinteraksi dengan produsen, calon konsumen, ataupun perantara pasar. Selain itu, pelaku usaha juga dapat memantau dan menyediakan segala kebutuhan dan keinginan dari calon konsumen. 


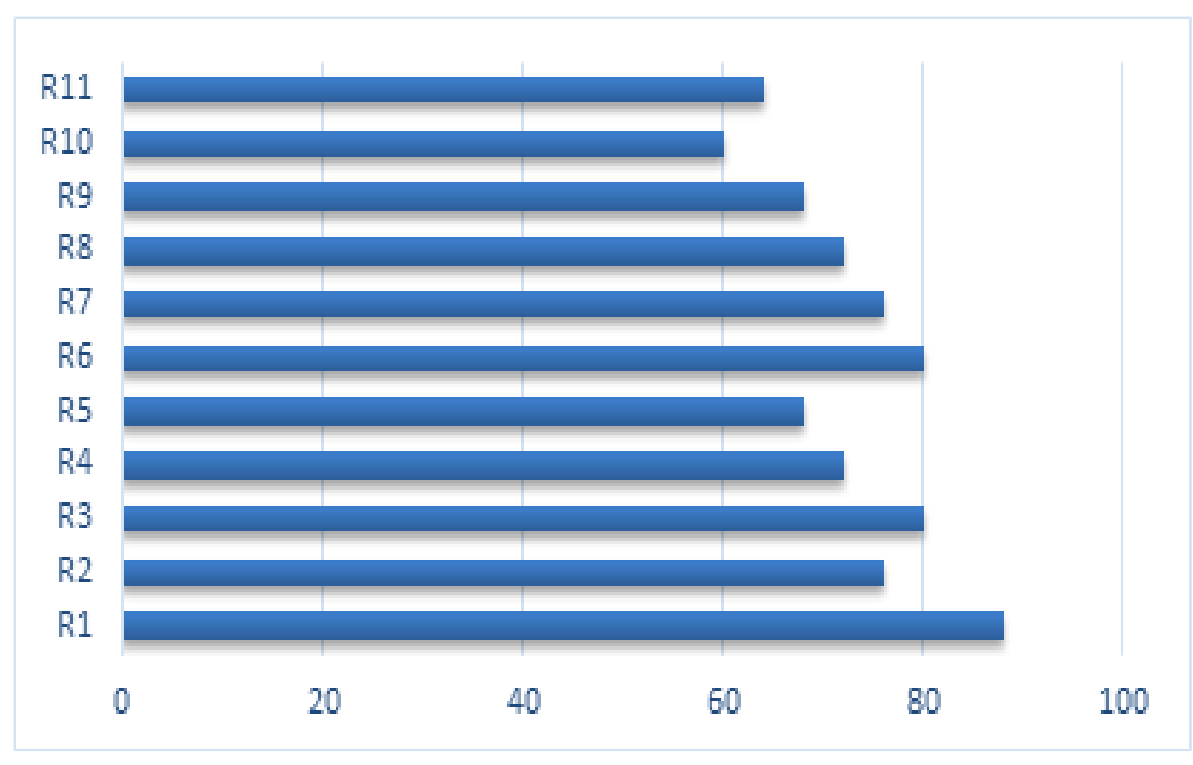

Gambar 1. Literasi Digital Marketing UMKM Kota Tasikmalaya

Dari hasil penelitian yang dapat dilihat pada Gambar 1, diketahui bahwa tingkat literasi digital marketing UMKM di Kota Tasikmalaya cukup rendah karena kurangnya pemahaman para pelaku UMKM mengenai digital marketing. 72,7\% mengetahui bahwa digital marketing adalah sosial media marketing, akan tetapi banyak pelaku usaha atau UMKM yang kurang mengetahui apa dan bagaimana menerapkan serta mengoptimalkan digital marketing. Hal itu dapat dilihat dari Gambar 1 dimana rata-rata skor atau nilai yang diperoleh mengenai pemahaman digital marketing adalah 73 dengan skor atau nilai terendah 60 dan tertinggi 88 .

Selain itu, para pelaku UMKM di Kota Tasikmalaya juga masih kurang optimal dalam menggunakan internet sehingga dalam memasarkan produk pun belum optimal. Hal tersebut ditandai dengan terbatasnya media promosi yang digunakan oleh para pelaku UMKM di Kota Tasikmalaya dimana media promosi yang digunakan yaitu WhatsApp, Instagram, dan Facebook.

Padahal saat ini sudah banyak sekali media promosi yang dapat digunakan oleh para pelaku usaha UMKM dengan mudah. Tetapi karena tingkat literasi digital marketing yang rendah menyebabkan para pelaku usaha yang ada di Kota Tasikmalaya mengalami kesulitan untuk menggunakan berbagai media promosi yang ada.

93\% UMKM di Kota Tasikmalaya tidak menggunakan website sebagai media promosi maupun media pemasaran untuk usahanya. Itu artinya, hanya $7 \%$ dari total keseluruhan UMKM di Kota Tasikmalaya yang menggunakan website sebagai media promosi dan juga sebagai media pemasaran pada usahanya. Selain itu, penggunaan $e$ commerce dalam pemasaran produknya masih berada di angka 6,4\%. Hal itu menunjukan tingkat literasi digital marketing UMKM di Kota Tasikmalaya secara keseluruhan berada pada tingkatan yang cukup rendah.

Rendahnya tingkat literasi digital marketing para pelaku usaha UMKM di Kota Tasikmalaya menyebabkan para pelaku usaha tersebut tidak dapat mengoptimalkan 
Mira Nurfitriya, Azizah Fauziyah, Tika Annisa Lestari Koeswandi, Ismail Yusuf, \& Nizza Nadya Rachmani

penggunaan internet untuk menjadi media pemasaran. Oleh karena itu, para pelaku usaha UMKM di Kota Tasikmalaya perlu meningkatkan literasi digital marketing salah satunya dengan cara mengikuti pelatihan.

\section{Perbedaan Tingkat Literasi Digital Marketing UMKM di Kota Tasikmalaya Sebelum dan Sesudah Pelatihan}

Hasil uji-t berupa Paired sample Test menunjukan bahwa nilai signifikansi sebesar 0.013, berarti kurang dari 0.05, maka Ho ditolak. Hal ini berarti bahwa hasil pemahaman literasi digital marketing peserta sebelum dan sesudah pelatihan tidak sama. Dengan demikian dapat dikatakan bahwa terdapat perbedaan yang signifikan antara hasil pemahaman literasi digital marketing sebelum dan sesudah pelatihan.

Tabel 1. Paired Sample T Test (sig-2-tailed)

\begin{tabular}{|l|c|c|c|c|c|}
\hline \multicolumn{1}{|c|}{ Tests } & N & Statistika Deskriptif & \multicolumn{3}{|c|}{ Paired T-Test } \\
\hline & & M (Std. D) & t & df & Sig. (2-tailed) \\
\hline Pre-Test & 11 & $73.09(8.02)$ & -3.00 & 10 & $.013^{*}$ \\
\hline Post-Test & 11 & $79.63(5.78)$ & & & \\
\hline
\end{tabular}

$*_{p}<0,05$ : nilai signifikansi

Perbedaan tersebut dapat dilihat dari hasil pretest dan postest dimana terdapat perbedaan nilai rata-rata pada pretest dan postest. Pada pretest nilai rata-rata yang diperoleh adalah 73.09 sedangkan pada postest nilai rata-rata yang diperoleh adalah 79,63. Selain itu, standar deviasi, nilai maxsimal dan nilai minimum juga terdapat perbedaan dimana pada pretest standar deviasi 8.02 , nilai maxsimal 88 , dan nilai minimum 60. Sedangkan pada postest standar deviasi 5.78, nilai maximal 88 , dan nilai minimum 72. Itu artinya pemahaman UMKM di Tasikmalaya mengenai digital marketing meningkat setelah adanya pelatihan.

Peningkatan literasi digital marketing memang sangat diperlukan bagi para pelaku UMKM saat ini. Dengan keterbatasan ruang interaksi saat ini, mengharuskan pelaku UMKM untuk terus berinovasi, salah satunya melalui pemasaran dengan pemanfaatan teknologi digital. Digitalisasi UMKM saat ini menjadi urgensi bagi berbagai pihak, baik pelaku UMKM itu sendiri maupun pemerintah. Oleh karena itu akses terhadap pelatihan-pelatihan amat sangat dibutuhkan sebagai upaya mengembangkan produk-produk UMKM yang ada saat ini.

\section{Penutup}

\section{Simpulan}

Berdasarkan hasil penelitian dan pembahasan di atas menunjukan bahwa tingkat literasi digital marketing Usaha Mikro Kecil dan Menengah (UMKM) di Kota Tasikmalaya cukup rendah, karena kurangnya pemahaman mengenai digital marketing, sehingga para pelaku usaha atau UMKM kurang optimal dalam penggunaan internet. Oleh karena itu, perlu ditingkatkan kembali dengan memberikan pelatihan. Karena berdasarkan uji hipotesis yang di analisis uji paired sample t-test 
berupa paired sample t-test (sig-2tailed) menunjukan bahwa nilai signifikansi sebesar 0.013 , berarti kurang dari 0.05 . Itu artinya terdapat perbedaan yang signifikan mengenai pemahaman pelaku usaha UMKM di Kota Tasikmalaya sebelum dan sesudah dilakukannya pelatihan literasi digital marketing.

\section{Saran}

Bagi pemerintah diharapkan untuk membuat sebuah program atau acara pelatihan mengenai digital marketing untuk para pelaku usaha atau UMKM khususnya yang berada di Kota Tasikmalaya. Sehingga UMKM dapat mengoptimalkan peran internet atau media pada usahanya dengan begitu para pelaku usaha UMKM di Kota Tasikmalaya dapat beradaptasi dengan pesatnya kemajuan teknologi di era industri 4.0 saat ini.

Mengingat jumlah peserta diluar target, diharapkan masyarakat dapat lebih berperan aktif dan antusias dalam pengembangan literasi digital marketing sehingga para pelaku usaha dapat bersaing dalam dunia perdagangan yang semakin ketat.

\section{DAFTAR PUSTAKA}

Afiyanti, Y. (2008). Focus group discussion (diskusi kelompok terfokus) sebagai metode pengumpulan data penelitian kualitatif. Jurnal Keprawatan Indonesia, 12(1), 58-62.

Ayodya, R. W. (2020). UMKM 4.0. Elex Media Komputindo.

Bawden, D. (2008). Origins and concepts of digital literacy, in digital literacies concepts, policies and practices. New York.

Belshaw, D. A. J. (2011). What is “digital literacy”. United Kingdom.

Direktorat Statistika Keuangan, Teknologi Informasi, dan Pariwisata. (2020). STATISTIK TELEKOMUNIKASI INDONESIA TELECOMUNICATION STATISTICS IN INDONESIA 2020. Badan Pusat Statistik

Harini, C. M. M. (2020). Strategi pemasaran kewirausahaan umkm. Media Sains Indonesia

Hitt, M. A. et all. (2001). Strategic management competitiveness and globlization. Cengange Learning.

Kitzinger, J., \& Barbour, R. S. (1999). Developing Focus Group Research: Politics, theory and practice. Sage Publication.

Lehoux, P., P, B., Daudelin, G. (2006). Focus group research and "the patient's view." Social Science \& Medicine, 63, 2091-2104.

Setiani, D. D., Nivanty, H., Lutfiah, W., \& Rahmawati, L. (2020). Fintech syariah: Manfaat dan problematika penerapan pada umkm. Jurnal Masharif al-Syariah: Jurnal Ekonomi dan Perbankan Syariah, 5(1). 
Mira Nurfitriya, Azizah Fauziyah, Tika Annisa Lestari Koeswandi, Ismail Yusuf, \& Nizza Nadya Rachmani

Streubert, H.J., Carpenter, R.R. (2003). Qualitative research in nursing: Advancing the humanistic imperative. Lippinctt.

Sulaksono, J. (2020). Peranan digital marketing bagi usaha mikro, kecil, dan menengah (umkm) desa tales kabupaten kediri. Generation Journal, 4(1), 4147.

Susanto, A., Sari, C. A., Rachmawanto, E. H., \& Mulyono, I. U. W. (2020). Implementasi facebook marketplace untuk produk umkm sebagai upaya peningkatan pemasaran dan penjualan online. Abdimasku: Jurnal Pengabdian Masyarakat, 3(1), 42-51.

Syahrianto, M. (2020). Pelaku umkm yang masuk marketplace baru 13\%. Warta Ekonomi: Jakarta.

Thaha, A. F. (2020). Dampak covid-19 terhadap umkm di indonesia. Jurnal Ilmiah Manajemen Pemasaran, 2(1), 147-153.

Wooliscroft, M. (1997). From Library User Education to Information Literacy: Some Issues Arising in This Evolutionary Process. 